ORIGINAL ARTICLE

\title{
Prevalensi masalah kesehatan mata di Puskesmas Kecamatan Kebon Jeruk
}

\author{
Fransisca Stefanie ${ }^{1}$
}

\begin{abstract}
ABSTRAK
\section{LATAR BELAKANG}

Gangguan penglihatan dan kebutaan masih menjadi masalah di Indonesia. Akibat dari gangguan penglihatan dapat mempengaruhi kualitas hidup penderita dan juga orang di sekelilingnya. Puskesmas sebagai pelayanan fasilitas kesehatan tingkat pertama memiliki peran dalam gangguan penglihatan dan kebutaan. Banyak usaha dilakukan untuk meningkatkan pengetahuan dan kesadaran masyarakat terhadap pentingnya menjaga kesehatan penglihatan. Upaya deteksi dini, pengobatan penyakit mata dan rujukan bagi kasus sulit telah dilakukan. Pencatatan kasus mata di Puskesmas juga memiliki peran di mana dapat memberikan informasi mengenai masalah kesehatan mata di fasilitas tingkat pertama. Penelitian ini bertujuan untuk mengetahui prevalensi masalah mata di Puskesmas Kecamatan Kebun Jeruk.
\end{abstract}

\section{METODE}

Penelitian ini menggunakan studi deskriptif observasional dengan desain potong lintang. Data diperoleh dari data sekunder. Sebanyak 320.809 pasien berkunjung ke Puskesmas Kecamatan Kebon Jeruk terhitung bulan Januari hingga Juli 2018. Dan kasus mata yang ditangani di Puskesmas sebanyak 3623 kasus. Hasil dianalisa dengan SPSS V21.

\section{HASIL}

Hasilnya adalah kasus mata terbanyak adalah kelainan lensa (39\%), kelainan konjungtiva (29\%), kelainan kelopak, sistem lakrimalis dan orbita $(22 \%)$, sebesar 3\% kelainan sklera, iris, dan korpus siliaris, kelainan koroid dan retina, dan glaukoma, dan sebesar 1\% kelainan korpus vitreus dan bola mata.

\section{KESIMPULAN}

Kelainan Lensa masih menjadi penyebab tertinggi masalah kesehatan Mata di Puskesmas Kecamatan Kebon Jeruk.

Kata kunci : masalah kesehatan mata, Puskesmas Kecamatan Kebon Jeruk
${ }^{1}$ Puskesmas Kecamatan Kebon

Jeruk

\section{Korespondensi:}

dr. Fransisca Stefanie

Puskesmas Kecamatan Kebon Jeruk Jalan Raya Kebon Jeruk No.2,

Kebon Jeruk, Jakarta Barat, 11510 Email: dr.fransiscastefanie@gmail. com

J Biomedika Kesehat 2018;1(2):140144

DOI: 10.18051/JBiomedKes.2018. v1.140-144

pISSN: 2621-539X / eISSN: 2621-5470

Artikel akses terbuka (open access) ini didistribusikan di bawah lisensi Creative Commons Attribution 4.0 International (CC-BY 4.0) 


\section{ABSTRACT}

\section{Prevalence of vision problems at Kebon Jeruk Public Health Care}

\section{BACKGROUND}

Vision problems and blindness are still become a common problems in Indonesia. These problems may also affect not only the patients life quality, but also the people around the patients. Public health care which acts as the first tier in providing health care solution also plays an important role in solving these issues. Lots of efforts is done in society to introduced and counducted to increase the knowledge and public awareness on the importance of keeping your eyes healthy. Early stage detection, treatment, and the cases referral due to the high complexity cases are also been done. This eye cases recorded for the public health care to provides helpful information that can be used for future needs. The study meant for evaluate the vision problem on Kebun Jeruk Public Health care.

\section{METHODS}

The study used an observational and descriptive study in cross sectional design upon 320,809 incoming patients since January until July 2018, with 3623 cases of ophthalmology. This research data analyzed by SPSS V21.

\section{RESULT}

Where in most cases, lens disorder with the most cases on $39 \%$ in portion, followed by conjunctival disorder $29 \%$, eyelid, lacrimal and orbital disorder $22 \%$, sclera, iris, ciliary body and glaucoma $3 \%$, and the rest is vitreal body and eye ball disorder $1 \%$.

\section{CONCLUSION}

The study showed lens disorder was the most cases in vision problem in Public Health care.

Keywords : vision problems, Kebon Jeruk Public Health Care

\section{PENDAHULUAN}

Mata adalah organ untuk melihat yang sangat penting dan dapat mempengaruhi kualitas hidup seseorang. ${ }^{(1)}$ Mata merupakan salah satu indra yang penting dalam menyerap informasi. Sebagai organ yang unik, melalui mata informasi dapat diserap sekitar $20 \%$. Namun, mata juga dapatmengalami gangguan, mulai dari gangguan ringan sampai yang berat di mana dapat terjadi kebutaan. (2) Lebih dari 90\% gangguan penglihatan di dunia terjasi di negara berkembang. ${ }^{(3,4)}$ Setiap menit terdapat satu orang mengalami kebutaan. Menurut WHO 285 juta orang mengalami gangguan penglihatan, di mana 39 juta mengalami kebutaan. Sesuai data tahun 2010, disebutkan juga bahwa $80 \%$ dari gangguan penglihatan dapat dicegah. ${ }^{(5)}$ Kedua penyebab utama dari gangguan penglihatan adalah gangguan refraksi (42\%), dan katarak $33 \%$. Semakin bertambahnya usia gangguan penglihatan juga semakin meningkat. . $^{(2,4)}$ Disebutkan bahwa $82 \%$ kebutaan $65 \%$ dengan gangguan sedang dan berat dialami oleh kelompok usia lebih dari 50 tahun. ${ }^{(2)}$

Prevalensi kebutaan nasional sebesar 0.4 persen, jauh lebih kecil dibanding prevalensi kebutaan tahun $2007 \quad(0.9 \%)^{(6)}$ Menurut survey kesehatan mata tahun 1982 prevalensi kebutaan sekitar 1.2\%, Riskesdas tahun 2007 sebesar $0.9 \%$, Riskesdas tahun 2013 sebesar $0.4 \%$ dengan validasi Perdami $0.6 \%$. (1) Prevalensi kebutaan pada usia 55-64 tahun sebesar 3.5\%, dan usia 74 tahun ke atas sebesar $8.4 \%$ di mana angka ini menunjukkan prevalensi yang di atas $0.5 \%$ sehingga masih menjadi masalah kesehatan masyarakat. ${ }^{(5)}$

Vison 2020 dicanangkan, merupakan inisiatif global dengan tujuan mengurangi jumlah penyakit mata yang dapat menyebabkan kebutaan. ${ }^{(3,7,8)}$ Tujuan yang ingin dicapai adalah mengeliminasi kebutaan pada gangguan mata yang dapat dicegah pada tahun $2020{ }^{(3)}$ WHO bersama dengan lebih dari 20 organisasi non pemerintah internasional yang terlibat dalam perawatan mata dan pencegahan dan manajemen kebutaan yang terdiri dari Badan Internasional untuk Pencegahan Kebutaan (IAPB). Untuk menanggulangi masalah kebutaan sendiri di Indonesia, Kemenkes telah mengembangkan strategistrategi mengenai Rencana Strategi Nasional Penanggulangan Gangguan Penglihatan dan Kebutaan untuk mensukseskan program Vision 2020. ${ }^{(7,8)}$

$$
\text { Upaya dalam menaggulangi }
$$

gangguan penglihatan di Indonesia merupakan tanggung jawab semua pihak. 
Berbagai usaha dilaksanakan untuk meningkatkan pengetahuan dan kesadaran masyarakat terhadap pentingnya menjaga kesehatan penglihatan. ${ }^{(9)}$ Data prevalensi dasar sangat penting untuk merencanakan strategi pencegahan kebutaan. $^{(3)}$ Upaya deteksi dini, pengobatan penyakit mata dan rujukan kasus-kasus yang tidak dapat ditangani juga dilakukan. Tidak terkecuali, puskesmas sebagai fasilitas kesehatan tingkat pertama memiliki peranan yang penting dalam penyelenggaraan upaya kesehatan masyarakat, di mana mengedepankan promotif dan preventif demi mencapai derajat kesehatan yang terbaik. Puskesmas sebagai ujung tombak pelayanan kesehatan mata di masyarakat dengan memperkuat sistem rujukan ke rumah sakit dan BKMM. ${ }^{(9)}$

Berdasarkan peran serta fasilitas kesehatan primer dalam pelayanan kesehatan mata, maka ingin diketahui jumlah masalah penyakit mata yang terdapat di Puskesmas Kecamatan Kebon Jeruk pada bulan JanurariJuli 2018.

\section{METODE}

Penelitian ini merupakan studi cross sectional dengan desain deskriptif observasional. Pengumpulan data menggunakan data sekunder rekam medis dari Puskesmas Kecamatan Kebon Jeruk dari bulan Januari - Juli 2018. Populasi adalah seluruh pasien yang berobat ke Puskesmas Kecamatan Kebon Jeruk pada bulan JanuariJuli 2018. Sampel yang diambil adalah seluruh pasien yang datang berobat dan mengalami masalah pada mata.

Semua data yang dikumpulkan dilakukan pengeditan dan dianalisa menggunakan SPSS V.21 dan disajikan dalam bentuk deskriptif melalui tabel dan diagram.

\section{HASIL}

Dari Tabel 1 dapat dilihat bahwa jumlah total kasus mata yang didapatkan di Puskesmas Kecamatan Kebon Jeruk sebesar 3623 kasus. Terbanyak adalah kasus kelainan lensa dengan jumlah 1409 kasus. Kelainan lensa di sini termasuk di antaranya adalah katarak, yang mana dilakukan pengobatan rujukan ke rumah sakit. Disusul berikutnya ada kasus kelainan konjungtiva sebanyak 1068 kasus, termasuk di antaranya adalah konjungtivits. Lalu kelainan kelopak, sistem lakrimalis, dan orbita sebanyak 783 kasus, kelainan koroid dan retina sebesar 120 kasus, glaukoma sebesar 117 kasus, sisanya kelainan sklera, iris, korpus siliaris sebesar 101 kasus, dan kelainan korpus vitreus dan bola mata sebanyak 25 kasus.

Pada Gambar 1 menunjukkan diagram di mana sebesar $39 \%$ penyakit mata merupakan kelainan lensa, sebanyak 29\% merupakan kelainan konjungtiva, sebesar $22 \%$ kelainan kelopak, sistem lakrimalis dan orbita. Sebanyak 3\% merupakan penyakit kelainan sclera, iris, korpus siliaris, kelainan koroid, retina, dan glaukoma. Sisanya sebanyak $1 \%$ adalah kelainan korpus vitreus dan bola mata.

\section{PEMBAHASAN}

Pada penelitian didapatkan kelainan lensa menjadi masalah kesehatan mata tertinggi di puskesmas kecamatan Kebun Jeruk yaitu mencapai 39\%. Hal ini sesuai

Tabel 1. Diagnosa Penyakit Sesuai ICD 10

\begin{tabular}{llc}
\hline \multicolumn{1}{c}{ ICD 10 } & \multicolumn{1}{c}{ Kelompok Penyakit } & n (\%) \\
\hline H $00-06$ & Kelainan kelopak, sistem lakrimalis, dan orbita & $783(22)$ \\
H $10-13$ & Kelainan konjungtiva & $1068(29)$ \\
H $15-22$ & Kelainan sklera, iris, dan korpus siliaris & $101(3)$ \\
H $25-28$ & Kelainan lensa & $1409(39)$ \\
H $30-36$ & Kelainan koroid dan retina & $120(3)$ \\
H $40-42$ & Glaukoma & $117(3)$ \\
H $43-45$ & Kelainan korpus vitreus dan bola mata & $25(1)$ \\
\hline Total & & $3623(100)$ \\
\hline
\end{tabular}


dengan penelitian Thapa $\mathrm{R}$ et $\mathrm{al}^{\left({ }^{(4)}\right.}$ yang menyatakan katarak menjadi penyebab tertinggi penurunan penglihatan yaitu mencapai $68 \%$ di Nepal, Bourne RRA et al. ${ }^{(10)}$ yang menyatakan pada tahun 2015 katarak merupakan penyebab penurunan penglihatan tertinggi di negara maju (Australia dan Eropa Tengah). Pascolini ${ }^{(11)}$ meyatakan katarak menjadi penyebab kebutaan yang utama (51\%), Correia $\mathrm{M}$ et al ${ }^{(12)}$ menyatakan katarak adalah penyebab kebutaan tertinggi di Timor Leste yaitu mencapai $79.4 \%$. Gamra HA et $\mathrm{al}^{(13)}$ juga menyatakan katarak dan glaukoma menjadi penyebab kebutaan tertinggi di Qatar. Berdasarkan data penyebab kebutaan tertinggi di Indonesia adalah Katarak. ${ }^{(7)} \mathrm{Hal}$ ini menunjukkan penanggulangan katarak oleh tindakan operasi yang baik sangatlah penting kurangnya untuk menurunkan angka kejadian katarak. ${ }^{(10)}$ Seluruh aspek harus membantu menekan faktor penghambat yang ada di Indonesia yaitu kurangnya kepedulian masyarakat, pemerintah dan organisasi non pemerintah, sehingga dapat memberantas buta katarak dan mensukseskan vision 2020. ${ }^{(7)}$

Masalahkesehatanmatatertinggikedua adalah kelainan konjungtiva. Pada penelitian ini tidak secara spesifik menyatakan kelainan konjuntiva yang menjadi penyebab. Namun konjungtivitis sering ditemukan sebagai kasus infeksi mata yaitu mencapai $2 \%$ dari populasi.

${ }^{(14)}$ Konjungtivitis dapat mengenai segala usia, seluruh tingkat ekonomi dan sosial. ${ }^{(15)}$ Kasus infeksi ini perlu diperhatikan karena walau pada sebagian kasus dapat sembuh dengan sendirinya namun sebagian lainnya dapat progresif dan menyebabkan komplikasi yang serius dan dapat menyebabkan gangguan penglihatan. ${ }^{(11)}$

Kelainan kelopak, lakrimal dan orbita menjadi masalah kesehatan mata ketiga yang ditemukan pada penelitian ini. Namun tidak dijelaskan secara luas apa saja yang menjadi penyebabnya.

Keterbatasan pada penelitian ini adalah data yang diperoleh berasal dari data sekunder, hasil pencatatan berdasarkan kelompok penyakit Jaminan Kesehatan Nasional yang tidak menguraikan jenis penyakit secara detail. Selain itru pemeriksaan tidak dilakukan oleh spesialis mata sehingga dapat menimbulkan kesalahan dalam menarik kesimpulan jenis kelompok penyakit mata dan hal ini adalah merupakan faktor yang dapat menimbulkan bias pada hasil penelitian ini.

Kasus kebutaan yang dapat dilakukan pencegahan mencapai $80 \% .^{(5,11)}$ Hal ini menunjukkan bahwa kebutaan dimasa yang akan datang dapat kita cegah bila seluruh aspek masyarakat dan pemerintah mulai melakukan

Gambar 1. Masalah Mata di Puskesmas Kecamatan Kebon Jeruk Bulan Januari - Juli 2018

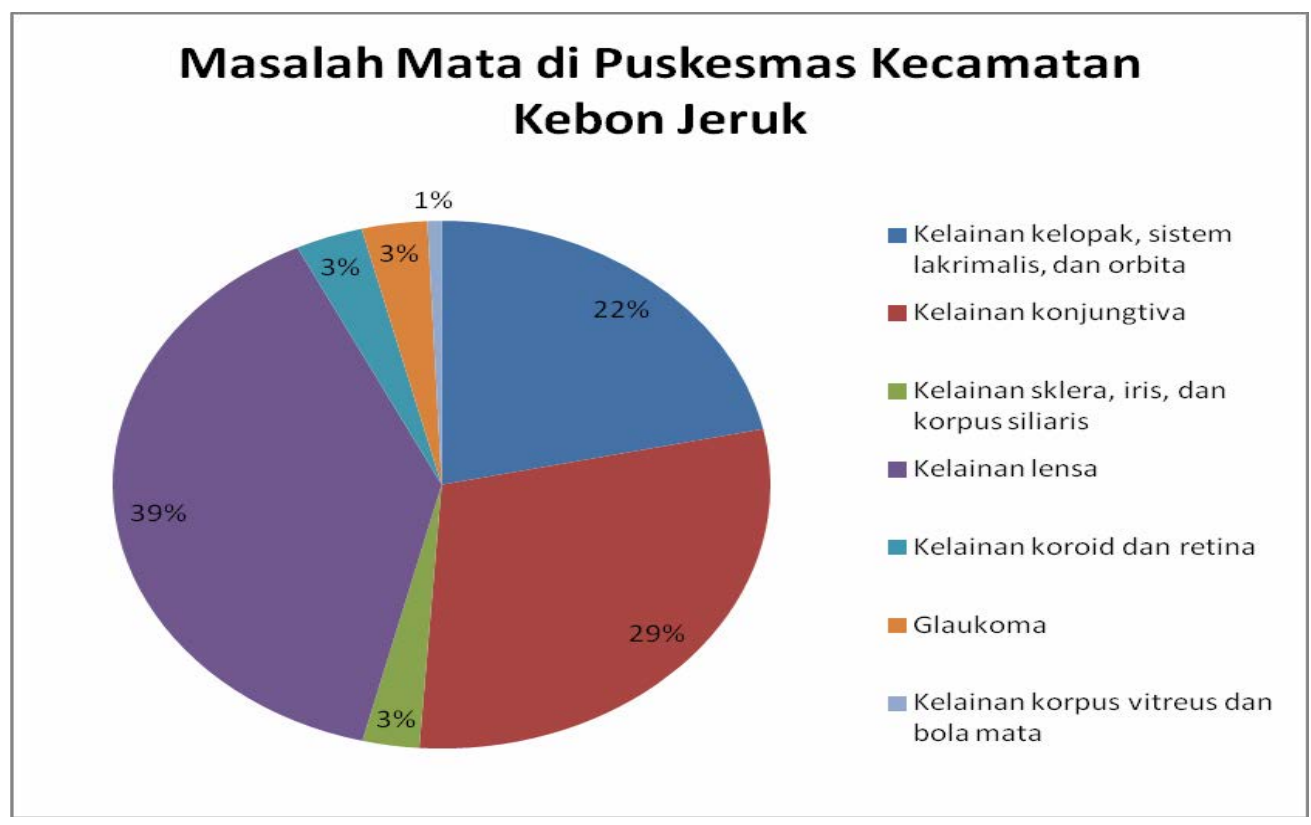


tindakan yang tepat sejak saat ini. Resnikoff et $\mathrm{al}^{(16)}$ menyatakan bahwa penurunan tajam penglihatan akan mempengaruhi kualitas hidup, pendidikan dan kesempatan pekerjaan. Hasil penelitian ini dapat digunakan untuk merencanakan tindakan apa yang sebaiknya dilakukan guna menekan angka kebutaan di masa yang akan datang.

Penelitian selanjutnya, disarankan untuk menggunakan metode analitik deskriptif untuk mencari analisa hubungan antara jenis kelamin, usia, dan faktor resiko yang berkaitan dengan masalah kesehatan mata. Selain itu pengumpulan data dapat lebih spesifik kepada diagnosis penyakit sehingga dapat dilakukan pencegahan yang lebih baik terhadap masalah kesehatan mata.

\section{KESIMPULAN}

Berdasarkan hasil dari penelitian yang sudah dilaksanakan maka dapat ditarik kesimpulan sebagai berikut. Kelainan lensa mata merupakan penyakit terbanyak yang ditemukan di Puskesmas Kecamatan Kebon Jeruk sebesar 39\% yaitu sebanyak 1409 pasien. Penyakit kedua terbanyak adalah kelainan konjungtiva sebesar 29\% atau sebanyak 1068 pasien, dan terbanyak ketiga adalah kelainan kelopak, sistem lakrimaslis, dan orbita sebesar $22 \%$ sebanyak 783 pasien, sebanyak 3\% merupakan kelainan koroid retina 120 pasien, sebesar 117 pasien menderita glaukoma,dan penyakit sclera, iris, korpus siliaris sebanyak 101 pasien. Terakhir sebanyak $1 \%$ adalah kelainan korpus vitreus dan bola mata atau sebanyak 25 pasien.

\section{DAFTAR REFERENSI}

1. Maryam A, Byrne M. Challenges and Solutions in Optical Ocular drug-delivery system. Expert Rev Clin Pharmacol. 2008; 1(1): 145-61. doi: 10.1586/17512433.1.1.145

2. Pusat Data dan Informasi Kementrian Kesehatan RI. Infodatin: Situasi Gangguan Penglihatan dan Kebutaan [Internet]. Jakarta: Pusat Data dan Informasi Kementrian Kesehatan RI; 2014. Available from: http://www.depkes.go.id/ resources/download/pusdatin/infodatin/infodatinpenglihatan.pdf

3. Ngondi J, Semple FO, Onsarigo A, et al. Prevalence and causes of Blindness and Low Vision in Southern Sudan. PloS Medicine. 2006; 3(12):0001-8. doi:10.1371/Journal.pmed.0030477

4. Thapa R, Bajimaya S, Paudya G, et al. Prevalence and causes of low vision and Blindness in an elderly population in Nepal: the Bhaktapur retina study. BMC Opthalmology. 2018;18(42):1-10. doi: $10.1186 / \mathrm{s} 12886-018-0710-9$

5. World Health Organization. Universal Eye Health: a global action plan 2014-2019 [Internet]. Spain: World Health Organization; 2013. Available from: http://www.who.int/blindness/AP2014_19_ English.pdf?ua=1

6. Badan Penelitian dan Pengembangan Kesehatan Kementrian Kesehatan RI. Riset Kesehatan Dasar 2013 [Internet]. Jakarta: Kemenkes RI; 2013. Available from: http://www.depkes. go.id/resources/download/general/Hasil\%20 Riskesdas\%202013.pdf

7. Vision 2020 di Indonesia, 2005. [cited 2018 Aug 18]. Available from: https://perdami.id/vision2020-indonesia/

8. World Health Organization. Blindness and Visual Impairment. [Internet]. World Health Organization; 2017 [cited 2018 Aug 19]. Available from: http://www.who.int/en/newsroom/fact-sheets/detail/blindness-and-visualimpairment

9. Kementrian Kesehatan Republik Indonesia. Data Dasar Puskesmas: Kondisi Desember 2016 [Internet]. Jakarta: Kemenkes RI; 2017 [cited 2018 Aug 19]. Available from: http://www.depkes. go.id/resources/download/pusdatin/data-dasarpuskesmas/2016/Buku\%20Data\%20Dasar\%20 Puskesmas\%202016.pdf

10. Bourne RRA, Jonas JB, Bron AM, et al. Prevalence and causes of vision loss in high-income countries and in eastern and central Europe in 2015: magnitude, tempral trends and projections. $\mathrm{Br}$ J Opthalmol. 2018;102:575-85. doi : 10.1136/ bjopthalmol-2017-311258

11. Pascolini D, Mariotti SP. Global estimates of visual impairment 2010. $\mathrm{Br} \mathrm{J}$ Ophthalmol. 2012;96(5):614-8. DOI: $\quad$ 10.1136/ bjophthalmol-2011-300539

12. Correia M, Das T, Magno J, et al. Prevalence and causes of blindness, visual impairment, and cataract surgery in Timor-Leste. Clinical Opthalmology. 2017;11:2125-31

13. Gamra HA, Mansouri FA, Khandekar R, et al Prevalence and causes of Blindness, Low vision and status of Cataract in 50 years and older citizen of Qatar-a community based survey. Opthalmic Epidemiologi. 2010;17(5):292-300. DOI: 10.3109/09286586.2010.508350

14. Solanke PV, Pawde P, P Valli. Prevalence of conjunctivitis among the Population of Kanyakumari District. International Journal of Contemporary Medical Research. 2017; 4(7):1466-7

15. Azari AA, Barney NP. Conjunctivitis: A systemic review of Diagnosis and Treatment. JAMA. 2013; 310(16): 1721-9. doi: 10.100/jama.2013.280318

16. Resnikoff S, Keys TU. Future trends in global blindness. Indian J Opthalmol. 2012;60(5):387-95 